\title{
Whole-Body Vibration in Automated Residential Solid Waste Collection
}

\author{
Helmut Paschold \\ Department of Safety Sciences, College of Health and Human Services, Indiana University of Pennsylvania, \\ Indiana, PA, USA. \\ Email: helmut.paschold@iup.edu
}

Received 21 September 2015; accepted 4 December 2015; published 7 December 2015

Copyright (C) 2015 by author and Scientific Research Publishing Inc.

This work is licensed under the Creative Commons Attribution International License (CC BY).

http://creativecommons.org/licenses/by/4.0/

(c) (i) Open Access

\begin{abstract}
Drivers of residential solid waste collection trucks are exposed to a wide variety of physical and health hazards. Automated robotic arm collection methods are intended to eliminate physical and ergonomic hazards associated with manual waste collection. However, whole-body vibration (WBV) exposure is a hazard that may be significant and greater than being found in semi-automated or manual methods. WBV is measured in a pilot field study of automated waste collection trucks during normal operation for nearly eight-hour periods on two consecutive days. All four trials are run under similar route conditions. Vibrations are measured at the seat-driver interface using a tri-axial accelerometer seat pad and portable vibration monitors. Measured WBV levels are compared with prior published data from waste collection trucks and health standards. The average WBV exposure value, corresponding to $0.99 \mathrm{~m} \cdot \mathrm{s}^{-2}$ for frequency-weighted r.m.s. acceleration, is above the ISO 2631-1 action value of $0.50 \mathrm{~m} \cdot \mathrm{s}^{-2}$ and below a limit value of $1.15 \mathrm{~m} \cdot \mathrm{s}^{-2}$ as given in the European Parliament Directive 2002/44/EC. This exposure level suggests the presence of potential health risks.
\end{abstract}

\section{Keywords}

Whole-Body Vibration, Municipal Solid Waste, Automated MSW Trucks

\section{Introduction}

Human exposure to whole-body vibration (WBV) is recognized as an occupational health risk factor, especially for lower back pain (LBP). Directive 2002/44/EC of the European Parliament recognizes worker risk from exposure to vibrations and the effects on the muscular/skeletal, neurological, and vascular systems [1]. Bovenzi and Hulshof [2] reported in a review of WBV epidemiological studies that there was clear evidence linking occupational WBV with increased risk of LBP. An epidemiological study of professional drivers found LBP fre- 
quency, intensity and disability increased significantly with increasing cumulative WBV exposure [3]. While acknowledging that LBP rates were higher for car drivers than non-drivers, and the contribution of WBV to car drivers' LBP was uncertain [4]. Schwarze [5] reported 27\% to $35 \%$ of 388 vehicle operators' LBP was linked to WBV, with the group of drivers exposed to high vibration doses having an LBP risk 1.55 times greater than the control group experiencing low vibration doses. The U.S. National Institute of Occupational Safety and Health (NIOSH), in a review of literature, found 15 of 19 WBV and LBP studies consistent in showing positive associations [6]. NIOSH assigned their highest ranking of "strong evidence" to the association between WBV and LBP, concluding with:

Laboratory studies had demonstrated WBV effects on the vertebra, intervertebral discs, and supporting musculature. Both experimental and epidemiologic evidence suggested that WBV might act in combination with other work-related factors such as prolonged sitting, lifting, and awkward postures to cause increased risk of back disorder (p. 6-33).

Guidelines for human WBV exposure could be found in Annex B of ISO 2631-1, Mechanical vibration and shock-Evaluation of human exposure to whole-body vibration [7]. Based upon the parameters of ISO 2631-1 Equation B.2, the action level for an 8-hour exposure was $0.5 \mathrm{~m} \cdot \mathrm{s}^{-2}$ and the upper level boundary for likely health risk was approximately $0.8 \mathrm{~m} \cdot \mathrm{s}^{-2}$. Directive 2002/44/EC of the European Parliament presented a WBV daily exposure action value of $0.5 \mathrm{~m} \cdot \mathrm{s}^{-2}$ and a limit value of $1.15 \mathrm{~m} \cdot \mathrm{s}^{-2}$ for the frequency-weighted r.m.s. acceleration [1]. The U.S. standard ANSI S3.18-2002 ISO 2631-1-1997 [8] adopted the ISO WBV standard [9]. Similarly, the ACGIH Threshold Limit Values were also based on the ISO standard [10]. Both ANSI and ACGIH standards were voluntary standards in the U.S. The Occupational Safety and Health Administration (OSHA) or OSHA approved State programs were responsible for the enforcement of mandatory standards being adopted as law. The OSHA general industry, maritime and construction standards did not include WBV [11].

Solid waste collection was recognized as a hazardous occupation. The 2012 lost-time and restricted-work accident rate for U.S. solid waste collection was over 2.7 times greater than the combined private industry sector rates [12]. WBV had been specifically identified as one of the many hazards facing refuse collection employees [13].

Residential solid waste collection is typically performed with trucks possessing a haulage capacity sufficient to reduce frequent trips to a landfill for off-loading, yet small enough to be maneuverable in urban traffic. These vehicles are likely to expose operators and passengers to WBV. Residential solid waste collection methods range from manual to semi-automated to automated (or mechanized) loading of waste. Manual collection and loading are typically accomplished by a work crew of two to three persons physically moving waste containers from a collection point and then lifting and dumping these into the hoppers of trucks. Semi-automated systems still require the manual movement and placement of the waste containers at the truck hopper by a work crew; however, a hydraulic or mechanical device lifts and empties the waste containers into the hopper. In the fully automated system, a driver operating a joystick controls robotic arm collects solid waste from containers, without leaving the vehicle cab. In this situation, the collection container is positioned at the curbside by the resident [14].

Manual and semi-automated solid waste collection vehicles expose drivers to similar WBV as with other commercial vehicles, such as delivery trucks. In the automated method, operators drive the truck, Figure 1, to an approximate alignment with the container and extend the robotic arm. This arm, as shown in Figure 2, grasps, lifts, and dumps the filled container into a hopper at the top of the truck, returning the container back to its curbside location. Automated operators are exposed to the vibrations generated by and transmitted from the robotic arm lifter operating perpendicular to the forward direction. The automated vehicles tend to have more stops and starts, compared to manual or semi-automated collection methods, as the driver aligns with each individual container.

Solid waste collection management eliminated manual material handling, walking, and direct contact with the solid waste by the implementation of the robotic arm collection system; however, the change may have introduced new ergonomic stressors due to joystick manipulation, neck and trunk-turning posture, and possible increases in WBV. While ergonomic stressors due to continuous poor posture (neck and trunk turning) and joystick maneuvering are fairly well recognized, few safety and health professionals in the US have an adequate awareness or understanding of WBV to assess the potential risk to workers [15]. NIOSH [6] reported epidemiological studies linking neck pain and awkward work posture, and also between neck disorders and forceful movements. Bovenzi [16] reported a significant association between neck pain and WBV exposure in a cohort study of professional drivers. Further study of the postural component during WBV exposure for automated 


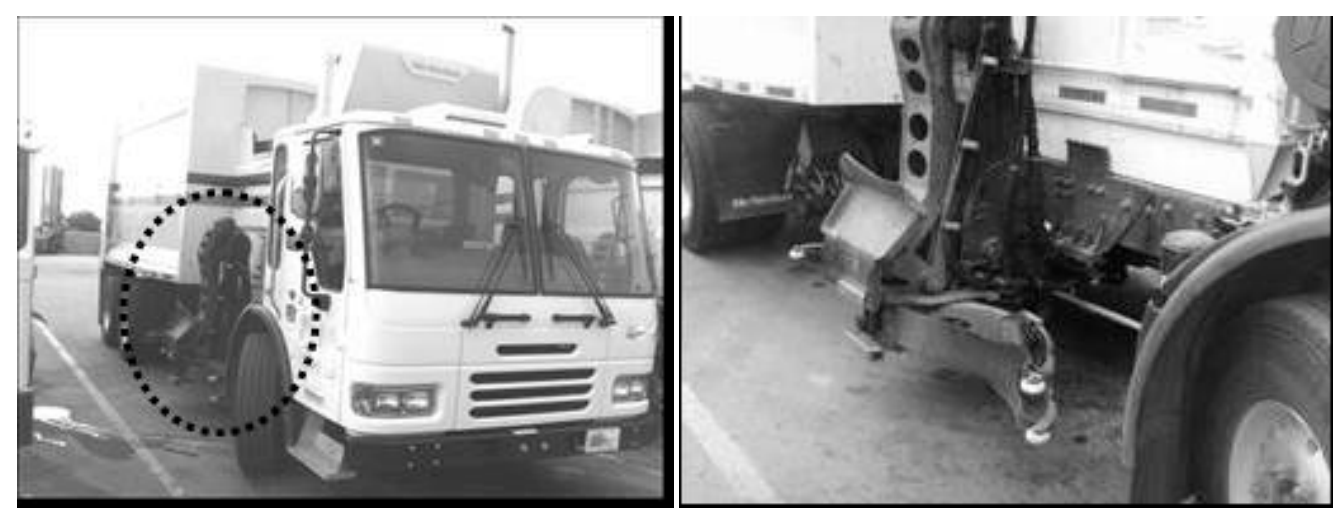

Figure 1. Automated collection truck with close-up of robotic arm on mid-section right-hand side of the vehicle.

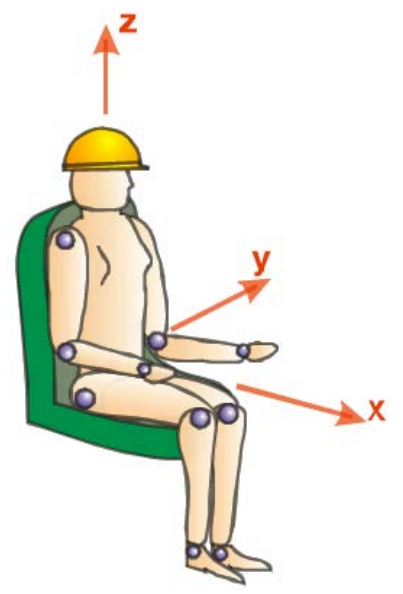

Figure 2. Depiction of seated X, Y, and Z axes (Source: Guide to good practice on Whole-Body Vibration,_11_08 WBV_Good_practice_Guide v6.7h English).

http://resource.isvr.soton.ac.uk/HRV/VIBGUIDE/2008_11_08\%20WBV_Good_practice_Guide\%20v6. 7h\%20English.pdf

waste collection drivers is warranted.

Three prior studies evaluated solid waste collection trucks and WBV levels [3] [17] [18]. Direct correspondence with the authors was required to categorize the type of waste collection methodology as to manual, semiautomated or automated. The earliest study of manual residential waste collection found WBV exposure exceeding recommended limits in Japan [17]. Two semi-automated collection studies were located: one in Portugal reported WBV doses exceeding the action value in 5 of 13 garbage trucks [18] and another in Italy found WBV levels below the action value in all six solid waste collection trucks [3]. No published WBV study results were found for residential solid waste collection in the U.S. or for automated collection elsewhere.

The objective of this study was to obtain measurements of WBV exposure to operators of automated residential solid waste collection vehicles at the contact interface between the driver and seat and compare these measurements with health risk guidelines. If a WBV health risk is apparent, further study of WBV source generation will be conducted to propose remedial actions.

\section{Methods}

\subsection{Solid Waste Collection Trucks and Routes}

The trucks monitored in this study were representative of the types used for automated collection. On Day 1, a 2007 Sterling Condor (\#1) and a 2003 Peterbilt (\#2) truck were monitored. On Day 2, the test was repeated on two 2007 Sterling Condors-one was the same vehicle and driver (\#1) as Day 1 and another 2007 Sterling 
Condor with a different driver (\#3). All trucks were equipped with the McNeilus 31-yard side loader compactor, Figure 1. Identical air ride seats were installed on the driver side of all trucks. The three drivers, of similar stature and weight, had been driving automated trucks for at least one year.

The trucks were run on their regular routes with no deviations from normal operation. The pre-trip inspections performed by the drivers indicated normal operating condition for all trucks. The four residential routes were within the same geographic area and shared level terrain, asphalt-paved roads in the residential area, similar spacing between homes, and similar distance from the landfill. The phases of the route included the start of the route at the garage/yard, travel to and from the collection area, collection, travel with a full load to the landfill, idling in queue to dump, dumping, travel return unloaded back to the collection area, and break time. Trips to the landfill for dumping were repeated up to three times during the workday.

\subsection{Vibration Measurement and Analysis}

Two Quest Technologies (Oconomowoc, WI) HAVPro Human Vibration Meters were used to obtain WBV measurements. The meters comply with ISO 8041:1990(E) (including Amendment 1:1999(E)) and ISO 26311:1997 requirements [19] and were factory calibrated within one year prior to use. The meters were set to run in WBV mode, automatically setting parameters in accordance with ISO requirements. A standardized axes orientation was as follows: $\mathrm{Y}$ - vertical, $\mathrm{X}$-fore and aft, and $\mathrm{Y}$ - transverse, shown in Figure 2. Settings included:

- $w_{k}$ weighting for the vertical (Z) axis;

- $w_{d}$ weightings for the horizontal (X and $\mathrm{Y}$ ) axes;

- a 1.4 multiplier for the horizontal axes.

The accelerometers were Quest Technologies Model 5313AQ tri-axial LIVM seat pad accelerometers connected via cable to the HAVPro instruments.

The HAVPro time history buffer is limited to 240 samples in a set; therefore it can hold up to a 20-minute total of continuous 5-second interval data in its time history. If data collection continues past the full-point of the buffer, the initial 5-second datum is eliminated to enter the newest incoming 5-second datum while still maintaining an on-going time weighted average. The HAVPro instrument will hold up to 100 data time history sets. To maintain datum, upon reaching the 20-minute storage limit of the time history buffer, the data set is saved as a data time history set and a new buffer data set is begun. In this manner, a continuous record of recordings of approximately eight hours can be achieved.

WBV data from the HAVPro meters was downloaded via an RS232 port and USB adaptor to a computer. This data was entered into the Quest Technologies Quest Suite Professional II software, Version 3.7.2269, for storage and analysis.

\subsection{Experimental Procedure}

The experiments were carried out over a two day period, July 31 and August 1, 2007, with three different trucks and drivers. As previously stated, one driver and truck pairing was repeated on the second day. Each trial run recording time limit was approximately eight hours.

For Day 1, a series of 24 individual 20-minute sets were recorded during the workday to allow viewing of 5-second interval data for the different phases of the collection task to avoid the overwriting of data on the HAVPro memory buffer. On Day 2, this setting was maintained for one truck and changed for the other. The setting change entailed a reduction of the interval time to 1-second, with the intent of increasing resolution of vibration data during the collection tasks. With 1-second intervals, each time history set was four minutes long; a total of 99 4-minute time history sets were recorded for a total of 6.6 hours.

During daylight hours on the day prior to the experiments, an initial survey of the truck cabs was conducted to determine optimal equipment layout to avoid interference with the driver during normal duties. As shown in Figure 2, the seat pad accelerometer was placed on the seat and aligned to the manufacturer's markings of X, Y, and $\mathrm{X}$ axes. Also, a small piece of tape was affixed to the front of the pad to assist with proper and easy directional alignment. On Day 1, the HAVPros and seat pad accelerometers were placed in two trucks just prior to the daily shift, at approximately 4:00 a.m. Tape was used to secure the meters from movement while stowed behind and below the driver seats in Figure 3. The drivers were instructed about the basic nature of the experiment and asked to not deviate from their routine route tasks. As each driver prepared to leave the truck yard, the HAVPro instruments were activated. On Day 1, one of the trucks was followed to observe operational practices for several 

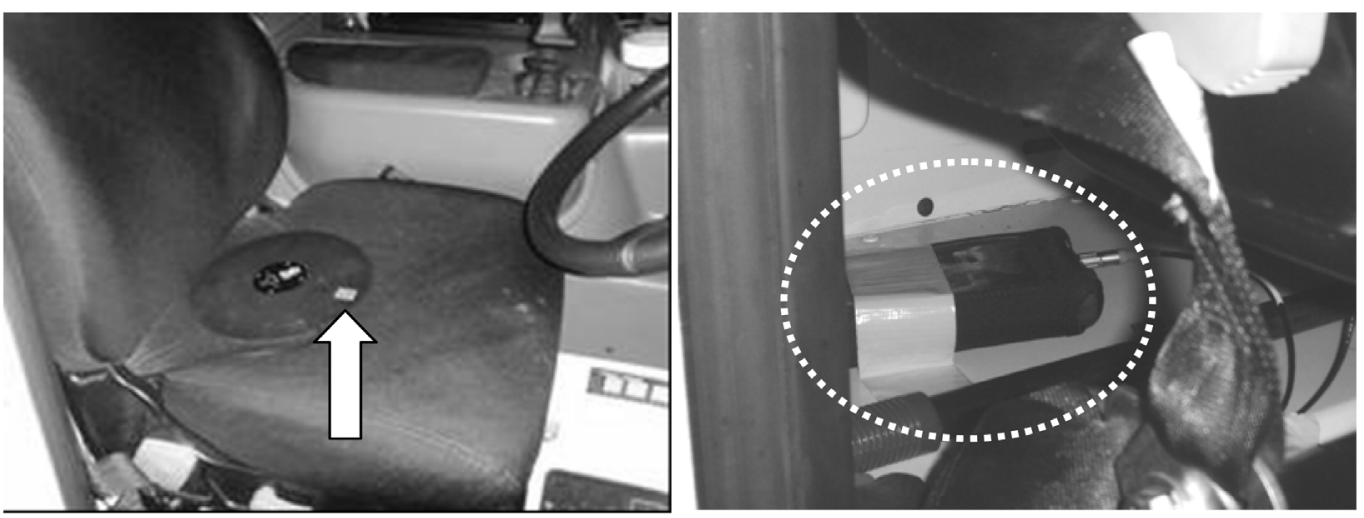

Figure 3. Seat pad accelerometer on driver seat and. HAVPro instrument secured behind and below the driver seat.

hours during the driving to the collection route and actual solid waste collection times. Truck logs were obtained to provide driver-recorded times of landfill delivery and unloading. The logs were compared with the graphic WBV results and verified the modes of operation during specific time periods. The instruments were retrieved from the trucks at the end of the workday. Data was downloaded into two separate computers, to assure backup in the event of one computer's failure.

To create a composite of the full-day individual time history sets, each data set for a given truck and day was combined to give a more accurate assessment of the total workday exposure. This was accomplished by using the data-combining feature of the Quest Technologies Quest Suite Professional II software. The individual time history sets were retained in original form to allow further detailed analysis of specific phases of the waste collection task such as during collection, unloading, etc.

\section{Results}

\subsection{Composite Findings}

A summary of the frequency weighted r.m.s. Aeq values in the $\mathrm{X}, \mathrm{Y}, \mathrm{Z}$, and $\mathrm{XYZ}$-sum axes is presented in Table 1 for the three different trucks over the 2-day period. The respective averages are presented at the bottom of the table. The four values for the XYZ-sum were all within $\pm 4 \%$ of the $0.99 \mathrm{~m} \cdot \mathrm{s}^{-2}$ average. The individual X, Y, and $\mathrm{Z}$ axis values for the trucks ranged from $0.36-0.40,0.35-0.46$, and $0.56-0.65$ respectively for the three axes; the widest distribution was noted in the Y-axis data. Table 1 also contains XYZ-sum axes Vibration Dose Value (VDV) ranging 3.31 to 9.77 and the Crest Factors (CF) 2.84 to 8.04.

\subsection{Waste Collection Phase Analysis}

Table 2 presents data for WBV during three phases of the collection operation. The driving-only phase started with a full load from the collection area to the landfill and appears to have included travel on some unpaved roads near the landfill. The unloading of the hopper at the landfill starts with the truck waiting in a queue to approach the active cell for dumping. This part is characterized by idling, moving, and dumping. The XYZ-sum vibration appears to be about the same for driving-only and collection (1.03 to 1.13 r.m.s.), and are higher than unloading segment ( 0.85 r.m.s.).

During waste collection which is approximately $75 \%$ of the workday, the $\mathrm{X}, \mathrm{Y}$ and $\mathrm{Z}$ axis values are relatively close to each other ranging from 0.36 to 0.58 r.m.s., with WBV only slightly higher in the $\mathrm{Z}$ axis. Also during collection, three of four $\mathrm{Y}$ and $\mathrm{Z}$ axes data sets were equal to or greater than the $0.50 \mathrm{~m} \cdot \mathrm{s}^{-2}$ action level. The meter settings of 5-second and 1-second averaging yielded similar results. Figures 4(a)-(b) graphically present a representative two-minute segment showing vibration during of the container collection process, measured on Truck \#1, Day 1. The heavy bold graph lines on top in Figure 4(a) and Figure 3(b) are the XYZ sum data, with the lighter lines representing the individual $\mathrm{X}, \mathrm{Y}$, and $\mathrm{Z}$ components. The peaks in the $\mathrm{Y}$ axis correspond to the dumping of the residential container into the truck hopper. $X$ axis peaks occur from the lurching of the truck as it starts and stops in short distances from house-to-house. 
Table 1. Frequency Weighted Acceleration $\mathrm{m} \cdot \mathrm{s}^{-2}$ (r.m.s.). Aeq and Vibration Dose Value $\left(\mathrm{m} \cdot \mathrm{s}^{-1.75}\right)$ for Fullday Combined Data Sets (5-second interval).

\begin{tabular}{cccccccc}
\hline $\begin{array}{c}\text { Truck } \\
\text { and day }\end{array}$ & $\begin{array}{c}\text { Measured } \\
\text { time (hr:min) }\end{array}$ & $\mathrm{X}$ & $\mathrm{Y}$ & $\mathrm{Z}$ & $\begin{array}{c}\mathrm{XYZ} \\
\text { sum }\end{array}$ & $\begin{array}{c}\text { VDV } \\
\text { XYZ sum }\end{array}$ & $\begin{array}{c}\text { CF } \\
\text { XYZ sum }\end{array}$ \\
\hline $1-1$ & $7: 43$ & 0.36 & 0.41 & 0.61 & 0.98 & 3.31 & 2.84 \\
$2-1$ & $8: 23$ & 0.36 & 0.35 & 0.65 & 0.95 & 8.53 & 3.04 \\
$1-2^{\mathrm{a}}$ & $6: 36$ & $0.38^{\mathrm{a}}$ & $0.44^{\mathrm{a}}$ & $0.59^{\mathrm{a}}$ & $1.01^{\mathrm{a}}$ & $5.92^{\mathrm{a}}$ & $8.04^{\mathrm{a}}$ \\
$3-2$ & $8: 13$ & 0.40 & 0.46 & 0.56 & 1.02 & 9.77 & 7.33 \\
Average & & 0.38 & 0.42 & 0.60 & 0.99 & & \\
SD & & 0.02 & 0.05 & 0.04 & 0.03 & & \\
\hline
\end{tabular}

${ }^{\mathrm{a}} 1$-second interval averaging.

Table 2. Frequency Weighted Acceleration $\mathrm{m} \cdot \mathrm{s}^{-2}$ (r.m.s.). Aeq for three 20-minute Operation Phase Segments (5-second interval), Truck \#1.

\begin{tabular}{|c|c|c|c|c|c|}
\hline Segment & Day/Time & $\mathrm{X}$ & $\mathrm{Y}$ & Z & XYZ-sum \\
\hline Collection & 7 - 31/2:20 a.m. & 0.36 & 0.50 & 0.57 & 1.03 \\
\hline Collection & 8 - 1/7:17 a.m. & $0.44^{\mathrm{a}}$ & $0.54^{\mathrm{a}}$ & $0.58^{\mathrm{a}}$ & $1.13^{\mathrm{a}}$ \\
\hline Driving & 7 - 31/9:00 a.m. & 0.20 & 0.32 & 0.89 & 1.03 \\
\hline Unloading & 7 - 31/9:20 a.m. & 0.27 & 0.31 & 0.65 & 0.85 \\
\hline
\end{tabular}

${ }^{\mathrm{a}} 1$-second interval averaging.
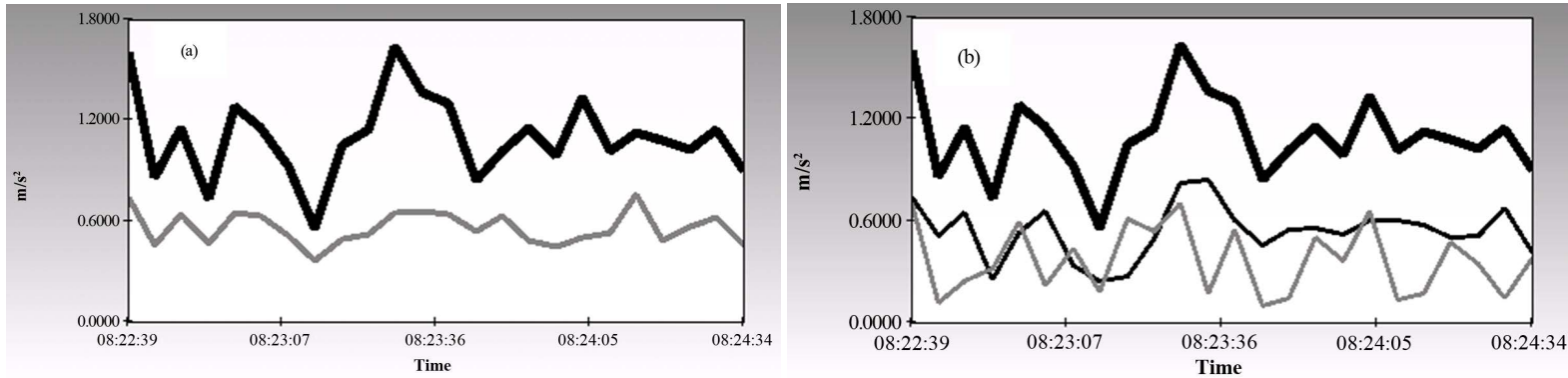

Figure 4. Measured vibration while collecting solid waste during a representative two minute interval on Day 1: (a) XYZ sum total and $\mathrm{Z}$ axis vibration; (b) XYZ sum total and $\mathrm{Y}$ and $\mathrm{X}$ axes.

$$
\mathrm{X} \text { axis. }
$$

\section{Discussion}

\subsection{General Results}

It would be expected that the WBV levels should be relatively similar for the four experiments as trucks were operated on or with identical seats, similar terrain, equivalent spacing of containers, and same distance from the landfill. Truck \#2 is of a different manufacturer than Trucks \#1 and \#3; however, all trucks were equipped with the identical McNeilus 31-yard side loader compactor. Truck \#3 has the highest $\mathrm{X}$ and $\mathrm{Y}$ axis value, the lowest $\mathrm{Z}$ axis value, and the highest $\mathrm{XYZ}$-sum value. The very slight differences in $\mathrm{Y}$ and $\mathrm{Z}$ axis values for Truck \#1 on Days 1 and 2 are explained by minor differences in collection conditions. Truck \#1-Day 2 data was recorded using 1-second averaging, resulting in a total data collection time of only 6.6 hours versus 8 hours for the three other experiments; however, results appear to be similar to the 5-second averages.

\subsection{Comparison with Prior Studies}

Table 3 shows a comparison of prior studies with the current findings. Bovenzi [3] reported a fairly low WBV 
Table 3. Comparison of findings with prior studies according to axis, $\mathrm{m} \cdot \mathrm{s}^{-2}$ (r.m.s.).

\begin{tabular}{cccccc}
\hline Study author & $\mathrm{X}$ & $\mathrm{Y}$ & $\mathrm{Z}$ & XYZ sum & Waste Collection type \\
\hline Bovenzi & 0.08 & 0.12 & 0.21 & 0.31 & Semi-automated \\
Maeda & 0.76 & 0.79 & 1.1 & & Manual \\
Melo & 0.17 & 0.19 & 0.43 & 0.60 & Semi-automated \\
Paschold & 0.38 & 0.42 & 0.60 & 0.99 & Automated \\
\hline
\end{tabular}

exposure and may reflect a waste collection method in which the driver frequently exits the truck to move and position the container at a hydraulic lifter. The Melo [18] study reported findings of higher WBV levels, based on a waste collection method identical to Bovenzi. Maeda [17] presented higher WBV levels and it appears that this study involved drivers spending more time driving the vehicle between the collection site and the landfill. An explanation for the difference in WBV levels between this experiment and the Bovenzi and Melo studies is found in the amount of time that the driver is actually in the driver's seat; for automated collection drivers, it is almost $100 \%$ of the work day. These reports did not specify the types of waste collection operations, seat types, CFs, or vibration measurement duration; limited operational detail was supplemented by direct contact with the authors. These missing details could provide further insight into the differences in measurement outcomes.

\subsection{Comparison with Health Standards}

In the absence of a U.S. regulatory standard, a comparison of findings is made with European minimum requirements for the protection of workers from exposure to mechanical vibration. European Directive 2002/44/ EC presents a daily exposure action value of $0.5 \mathrm{~m} \cdot \mathrm{s}^{-2}$ and a limit value of $1.15 \mathrm{~m} \cdot \mathrm{s}^{-2}$. All four measurements showed exposure to be above the action value and below the limit value. According to ISO 2631-1:1997(E), values in the action level zone present potential health risks that require attention. Precise assessment of risk within the action level zone is currently not possible; however, it should be noted the average XYZ-sum value, $0.99 \mathrm{~m} \cdot \mathrm{s}^{-2}$, was only $15 \%$ below the limit value that suggests health risks are likely.

The ISO standard states that the WBV assessment is made independently for each axis and the health risk evaluated according to the highest single axis value. However, section 7.2.2 explains when two or more of the axes vibration magnitudes are similar (not defined in the standard), the vector sum can be used for health risk assessment.

The four CF values are below the 9.0 threshold contained in ISO 2631-1:1997(E). If the 9.0 threshold were exceeded, the r.m.s. values could be considered invalid and exposure would have to be determined by the VDV method.

\subsection{Limitations}

This study measured four vehicles, a small sample size relative to the number of trucks. However, the results were fairly consistent. The 1997 ISO standard requires an adequate monitoring duration to assure precision and representation of typical exposure. This study differs from the prior solid waste collection truck and many other WBV studies, as an entire work day of monitoring was completed and has many combined sample sets of WBV data (up to eight hours).

Many other variables in a full scale study should be recorded and included such as driver anthropometry, seat type and adjustment, vehicle conditions (tire pressure, shock system, differing models, etc.), roads, driving speeds, variations in residential waste loads, and so on.

\section{Conclusion}

This study finds that automated residential waste collection drivers are exposed to WBV levels associated with an increased health risk while working in a seated position [3] [7]. When this study's higher values are compared to previously reported WBV values for solid waste truck operation those of Bovenzi [2] and Melo [18] in semi-automated operations, they are most likely explained by the robotic arm activity and more frequent starts and stops attributed to the nature of automated collection as compared to semi-automated or manual collection. 
Also, the driver of the automated truck is in the vehicle virtually $100 \%$ of the work day. The $\mathrm{X}$ and $\mathrm{Y}$ axes levels are higher during collection than while driving; $\mathrm{Z}$ axis values are lower in collection than driving; and XYZ-sum values are equivalent for collection and driving. This study identifies a need to obtain improved operation mode detail from the operator or an assigned observer. Additional variables to consider for further research include the effects of operator posture, collection route characteristics (terrain, roads, home spacing), equipment type, and seat transmission (seat type, condition, adjustment).

\section{References}

[1] European Parliament and the Council of the European Union (2002) Directive 2002/44/EC of the European Parliament and of the Council of 25 June 2002.

http://www.vibrationdirective.com/media/pdfs/translation-english-ec-vibration-directive.pdf

[2] Bovenzi, M. and Hulshof, C. (1998) An Updated Review of Epidemiologic Studies on the Relationship between Exposure to Whole-Body Vibration and Low Back Pain. Journal of Sound and Vibration, 215, 595-611. http://dx.doi.org/10.1006/jsvi.1998.1598

[3] Bovenzi, M., Rui, F., Negro, C., D’Agostin, F., Angotzi, G., Bianchi, S., Bramanti, L., Festa, G., Gatti, S., Pinto, I., Rondina, L. and Stacchini, N. (2006) An Epidemiological Study of Low Back Pain in Professional Drivers. Journal of Sound and Vibration, 298, 514-539. http://dx.doi.org/10.1016/j.jsv.2006.06.001

[4] Gallais, L. and Griffin, M. (2006) Low Back Pain in Car Drivers: A Review of Studies Published 1975 to 2005. Journal of Sound and Vibration, 298, 499-513. http://dx.doi.org/10.1016/j.jsv.2006.06.012

[5] Schwarze, S., Notbohm, G., Dupuis, H. and Hartung, E. (1998) Dose-Response Relationships between Whole-Body Vibration and Lumbar Disk Disease-A Field Study of 388 Drivers of Different Vehicles. Journal of Sound and Vibration, 215, 613-218. http://dx.doi.org/10.1006/jsvi.1998.1602

[6] National Institute of Occupational Safety and Health (NIOSH) (1997) Musculoskeletal Disorders and Workplace Factors. DHHS (NIOSH) Publication, Cincinnati, 97-141.

[7] International Organization for Standardization (ISO) (1997) 2631-1, Mechanical Vibration and Shock—Evaluation of Human Exposure to Whole-Body Vibration-Part 1: General Requirements.

[8] American National Standard Institute (ANSI) (1997) S3.18-2002 ISO 2631-1-1997, Mechanical Vibration and Shock-Evaluation of Human Exposure to Whole-Body Vibration-Part 1: General Requirements.

[9] Mansfield, N. (2005) Human Responses to Vibration. CRC Press LLC, Boca Raton.

[10] American Conference of Governmental Industrial Hygienists (ACGIH) (2001) Documentation of the Threshold Limit Values for Physical Agents. ACGIH, Cincinnati.

[11] Occupational Safety and Health Administration (OSHA). General Industry Standards, Construction, and Maritime. Accessed 16 April 2014. www.ohsa.gov

[12] Bureau of Labor and Statistics. BLS Incidence Rates of Nonfatal Occupational Injuries and Illnesses by Industry and Case Types. Searched 9 April 2014. www.bls.gov

[13] Kuijer, P. and Frings-Dresen, M. (2004) World at Work: Refuse Collectors. Occupational and Environmental Medicine, 61, 282-286. http://dx.doi.org/10.1136/oem.2002.001172

[14] Theisen, H. (2002) Collection of Solid Waste. In: Tchobanoglous, G. and Kreith, F., Eds., Handbook of Solid Waste Management, Second Edition, McGraw-Hill, New York, 7.1-7.27.

[15] Paschold, H. and Seergeev, A. (2009) Whole-Body Vibration Knowledge Survey of U.S. Occupational Safety and Health Professionals. Journal of Safety Research, 40, 171-176. http://dx.doi.org/10.1016/j.jsr.2009.02.008

[16] Bovenzi, M. (2013) A Prospective Cohort Study of Neck and Shoulder Pain in Professional Drivers. Proceedings of the 5th International Conference on Whole Body Vibration Injuries, Amsterdam, 5-7 June 2013.

[17] Maeda, S. and Morioka, M. (1998) Measurement of Whole-Body Vibration Exposure from Garbage Trucks. Journal of Sound and Vibration, 215, 959-964. http://dx.doi.org/10.1006/jsvi.1998.1676

[18] Melo, R. and Carvalhinho, F. (2006) Whole-Body Vibration Exposure of Waste Truck Drivers. Proceedings of the IEA 2006 16th World Congress on Ergonomics, Maastricht, 10-14 July 2006.

[19] Quest Technologies (2005) HAVPro Personal Vibration Monitor Owner’s Manual. Quest Technologies, Inc., Ocononowoc. 